\title{
Post-buckled precompressed (PBP) elements: a new class of flight control actuators enhancing high-speed autonomous VTOL MAVs
}

\author{
Ron Barrett $^{{ }^{a}, \mathrm{~b}} \quad$ Ross McMurtry $^{{ }^{*} \mathrm{ac}}$ Roelof Vos ${ }^{\mathrm{a}, \mathrm{b}} \quad$ Paolo Tiso $^{{ }^{* a}} \quad$ Roeland De Breuker $^{{ }^{*} \mathrm{a}}$ \\ ${ }^{a}$ Faculty of Aerospace Engineering, Technical University of Delft, Netherlands \\ ${ }^{\mathrm{b}}$ Aerospace Engineering Department, Auburn University, Alabama \\ ${ }^{\mathrm{c}}$ Imperial College, London, UK
}

\begin{abstract}
This paper describes a new class of flight control actuators using Post-Buckled Precompressed (PBP) piezoelectric elements. These actuators are designed to produce significantly higher deflection and force levels than conventional piezoelectric actuator elements. Classical laminate plate theory (CLPT) models are shown to work very well in capturing the behavior of the free, unloaded elements. A new high transverse deflection model which employs nonlinear structural relations is shown to successfully predict the performance of the PBP actuators as they are exposed to higher and higher levels of axial force, which induces post buckling deflections. A proof-of-concept empennage assembly and actuator were fabricated using the principles of PBP actuation. A single grid-fin flight control effector was driven by a $3.5 "(88.9 \mathrm{~mm})$ long piezoceramic bimorph PBP actuator. By using the PBP configuration, deflections were controllably magnified 4.5 times with excellent correlation between theory and experiment. Quasi-static bench testing showed deflection levels in excess of $\pm 6^{\circ}$ at rates exceeding $15 \mathrm{~Hz}$. The new solid state PBP actuator was shown to reduce the part count with respect to conventional servoactuators by an order of magnitude. Power consumption dropped from $24 \mathrm{~W}$ to $100 \mathrm{~mW}$, weight was cut from $108 \mathrm{~g}$ to $14 \mathrm{~g}$, slop went from $1.6^{\circ}$ to $0.02^{\circ}$ and current draw went from $5 \mathrm{~A}$ to $1.4 \mathrm{~mA}$. The result was that the XQ-138 subscale UAV family experienced nearly a $4 \%$ reduction in operating empty weight via the switch from conventional to PBP actuators while in every other measure, gross performance was significantly enhanced.
\end{abstract}

Keywords: Piezoelectric Flight Control Grid Fin Post-Buckled Precompressed MAV UAV

Symbol
a
A, B, D
AR
b
c
E
M
N
t
y
Z
$\alpha$
$\delta$
$\delta_{0}$
$\varepsilon$
$\kappa$
$\Lambda$
$\sigma$

NOMENCLATURE

$\begin{array}{cc}\begin{array}{c}\text { Description } \\ \text { integrating factor }\end{array} & \text { Units } \\ \begin{array}{c}\text { in-plane, coupled, bending laminate stiffnesses } \\ \text { PBP Amplification Ratio }=\delta\left(\mathrm{F}_{\mathrm{a}}>0\right) / \delta\left(\mathrm{F}_{\mathrm{a}}=0\right)\end{array} & \mathrm{lb} / \mathrm{in}, \mathrm{lb} \text {, in-lb }(\mathrm{N} / \mathrm{m}, \mathrm{N}, \mathrm{N}-\mathrm{m}) \\ \text { actuator width } & \mathrm{in}(\mathrm{mm}) \\ \text { integrating factor } & \mathrm{GPa}(\mathrm{msi}) \\ \text { stiffness } & \mathrm{N}-\mathrm{m} / \mathrm{m}(\mathrm{in}-\mathrm{b} / \mathrm{in}) \\ \text { applied moment vector } & \mathrm{N} / \mathrm{m}(\mathrm{lb} / \mathrm{in}) \\ \text { applied force vector } & \text { in }(\mathrm{mm}) \\ \text { thickness } & \text { in }(\mathrm{mm}) \\ \text { out of plane displacement dimension } & \text { in }(\mathrm{mm}) \\ \text { through thickness dimension } & \mathrm{deg} \\ \text { angle of attack } & \mathrm{deg} \\ \text { PBP beam angle } & \mathrm{deg} \\ \text { PBP end rotation angle } & \mu \mathrm{strain} \\ \text { laminate in-plain strain } & \mathrm{rad} / \mathrm{in}(\mathrm{rad} / \mathrm{m}) \\ \text { laminate curvature } & \mu \mathrm{strain} \\ \text { piezoelectric free element strain } & \mathrm{msi}(\mathrm{GPa}) \\ \text { stress } & \end{array}$

Subscripts

$\begin{array}{cc}\mathrm{a} & \text { actuator } \\ \mathrm{b} & \text { bond } \\ \mathrm{ex} & \text { external } \\ 1 & \text { laminate } \\ \mathrm{s} & \text { substrate } \\ \mathrm{t} & \text { thermally induced }\end{array}$




\section{INTRODUCTION}

For nearly a hundred years, the fundamental properties of piezoelectric elements have been successfully modeled. Many different classes of actuators from sonar to stereo tweeters to helicopter rotor blade elements have been made using piezoelectric sheets, stacks and blocks as driving elements. ${ }^{1}$ Numerous studies have been centered on the addition of various types of mechanisms, the use of different lamination techniques and/or shapes to amplify either deflection at the expense of force or force at the expense of deflection. ${ }^{2-7}$ In each case some finite amount of total work was lost in the conversion process while weight, volume, complexity and cost penalties were incurred. Because many classes of aircraft have extremely tight weight, volume and performance requirements, they tend to drive actuators to smaller packages with higher levels of performance. Several other classes of piezoelectric actuators to be investigated as of late employ dynamic effects of oscillating piezoelectric, electrostrictive and/or magnetostrictive elements in linear- and rotary-inchworm type motors. Although well suited for some applications, their system-level power densities, bandwidths, form factors and costs are currently not compatible with some of the most demanding classes of aircraft.

Among these most demanding types of aircraft are the small uninhabited aerial vehicles (UAVs), known as mini- or micro-aerial vehicles (MAVs). Similarly, guided hard-launched munitions also present similar challenges to the design engineer with bandwidths ranging in excess of $300 \mathrm{~Hz}$ at setback accelerations of upwards of $100,000 \mathrm{~g}$ 's. In recent years, these extreme requirements in bandwidth, weight, volume, environmental and deflection requirements have lead to the development of new, high performance actuators which are specifically tailored to these types of aircraft. ${ }^{8-10}$ Figure 1 shows the first MAV which was enabled by piezoelectric Flexspar flight control actuators.
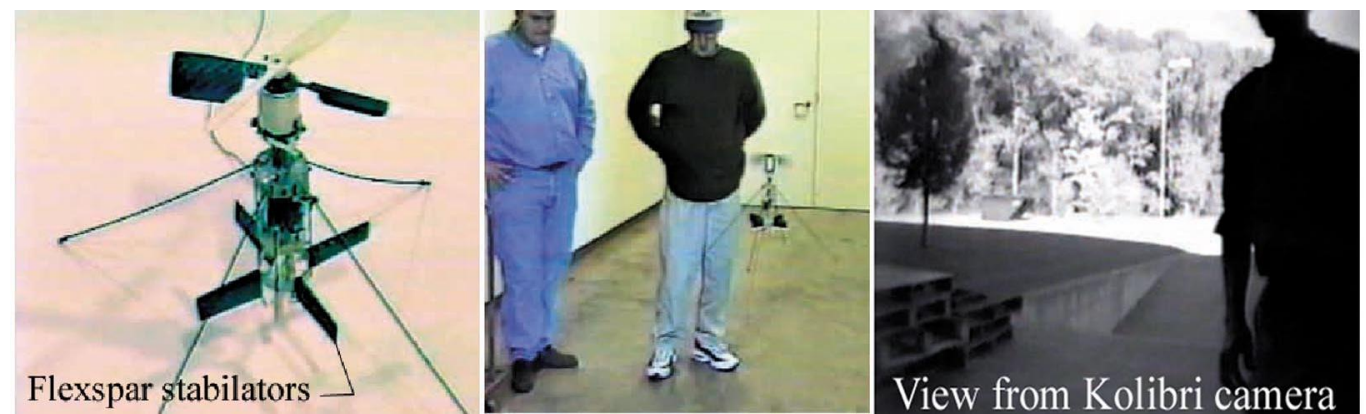

Fig. 1 The Lutronix Kolibri, the World's First VTOL MAV Enabled by Piezoelectric Flexspar Stabilators (1997) ${ }^{11}$

Although these actuators have been shown to work for many classes of aircraft, their performance could be improved still further. Although previously unpublished, it is well known by those who work with many of these classes of flight control actuators, that deadband, slop and power density are often challenging issues for the design engineer to work around.

One of the most capable UAVs which has been developed to date is the XQ-138. ${ }^{11}$ The XQ-138 is designed to take-off and land vertically, hover like a helicopter, then pitch over and transition to airplane-mode flight for dash out, cruise and loiter to speeds in excess of several hundred kts. Because this class of convertible UAVs is also intended to operate in urban and forested environments in any type of weather, the demands on the flight control assembly are extremely high. Accordingly, the purpose of this paper is to lay out a new class of actuator which is designed to significantly enhance the overall performance of the XQ-138 while decreasing actuator weight and volume fractions thereby opening up total useful load.

Because nearly all actuator schemes which have employed piezoelectric actuators have been centered on various arrangements that trade force for stroke while degrading the total work available, a new approach is needed. In the late' 90 's Lesieutre conceived a piezoelectric transformer which was designed with axially compressed piezoelectric elements. ${ }^{12}$ The axial compression levels were close to the buckling load which effectively nulled some of the loss generating mechanism inherent in most piezoelectric actuator designs. References 12 and 13 showed that by doing this, the overall energy conversion efficiency of the entire system could be made higher than the efficiency of the raw material itself. Accordingly, this paper lays out several years of research which have been centered on improving and bringing this fundamental discovery to the aerospace flight controls community. 


\section{ANALYTICAL MODELING}

\subsection{Generic Actuator Set-Up}

To take advantage of the principles laid out in Ref. 12 and 13, a piezoelectric bender element is arranged in a pin-pin configuration with an externally applied axial force which is close to the perfect column buckling load. The axial force, $F_{a}$, is applied so that as the piezoelectric moment is applied, a controlled "imperfection" induces further, but controlled deformation. The overall goal of this Post-Buckled Precompressed (PBP) actuator assembly is to simultaneously and controllably amplify both the force and deflection levels which can be generated by solid state piezoelectric bender elements. The addition of various forms of compliant mechanisms on either end of the actuator allow for a higher level of controllability, but generally retard the ultimate deflection levels so the size, weight and complexity of such mechanisms are typically minimized. Because essentially any level of deflection can be excited via the application of ever higher loads, great care is taken in the design as the external face of the convex actuator element will suffer from various forms of tensile failure including depoling and mechanical fracture if the bending levels are too high. Figure 2 shows the overall arrangement of the actuator including the pin-pin supports, axial force and generic end extensions.

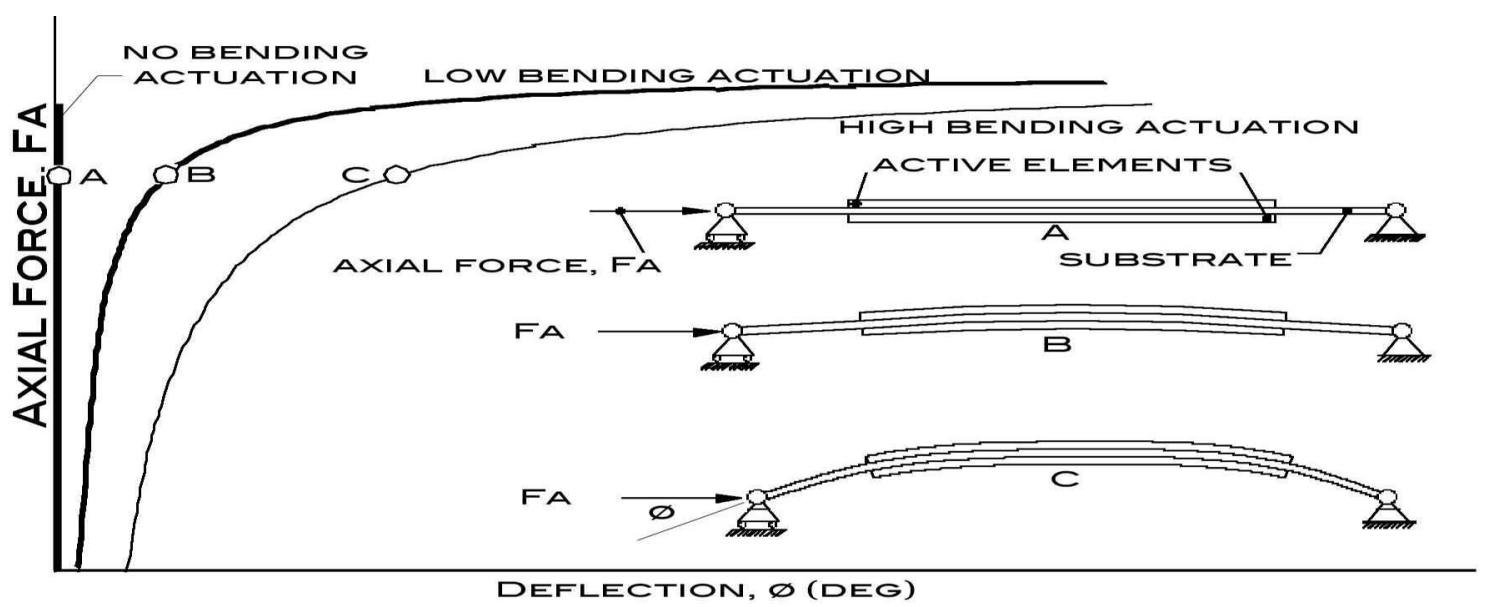

Figure 2 Generic Arrangement of the Post-Buckled Precompressed (PBP) Actuator Arrangement

The static behavior of the unloaded PBP bender element is easily captured by using classical laminated plate theory (CLPT) models. The bender is made from two primary components: a pair of piezoelectric actuator sheets bonded to a structurally stiff substrate. As the piezoelectric sheets are commanded to alternatively expand and contract, the bender element deflects up and down. An important aspect of the design involves the use of coefficient of thermal expansion (CTE) mismatch which has been used for more than 20 years to precompress tension-sensitive piezoceramic elements and pretension usually metallic isotropic substrates. ${ }^{710}$ The static, unloaded $\left(\mathrm{F}_{\mathrm{a}}=0\right)$ behavior of the device can be modeled easily by the techniques described in Ref. 1 and 14 . Assuming an unloaded structure and using CLPT methods, the following holds. The applied forces and moments may be balanced by stress distributions which are distributed through the thickness of the element:

$$
\mathrm{N}=\int \sigma \mathrm{dz} \quad \mathrm{M}=\int \sigma \mathrm{zdz}
$$

Actuator in-plane forces and moments (a) can be expressed as a balance with external forces and moments (ex) and forces and moments due to mismatches in coefficients of thermal expansion (t). These factors will generate in-plane laminate strains, $\varepsilon$ and curvatures, $\kappa$. 


$$
\left\{\begin{array}{l}
\mathrm{N} \\
\mathrm{M}
\end{array}\right\}_{\mathrm{ex}}+\left\{\begin{array}{l}
\mathrm{N} \\
\mathrm{M}
\end{array}\right\}_{\mathrm{a}}+\left\{\begin{array}{l}
\mathrm{N} \\
\mathrm{M}
\end{array}\right\}_{\mathrm{t}}=\left[\begin{array}{ll}
\mathrm{A} & \mathrm{B} \\
\mathrm{B} & \mathrm{D}
\end{array}\right]_{1}\left\{\begin{array}{l}
\varepsilon \\
\kappa
\end{array}\right\}_{1}
$$

If the external forces and moments are ignored and thermally induced stresses are not considered, equation 2 can be reduced to:

$$
\left[\begin{array}{ll}
A & B \\
B & D
\end{array}\right]_{l}\left\{\begin{array}{l}
\varepsilon \\
\kappa
\end{array}\right\}=\left[\begin{array}{ll}
A & B \\
B & D
\end{array}\right]_{a}\left\{\begin{array}{l}
\Lambda \\
0
\end{array}\right\}
$$

At this point, equation 3 can be easily solved for laminate curvature, $\kappa$, by assuming that a balanced, symmetric laminate composed of isotropic or quasi-isotropic elements are used:

$$
\kappa=\frac{B_{a}}{D_{l}} \Lambda
$$

By using the unloaded laminate curvature, $\kappa$, as a starting point, the problem can now be defined in terms of gross curvatures with externally applied axial force, $\mathrm{F}_{\mathrm{a}}$, as follows:

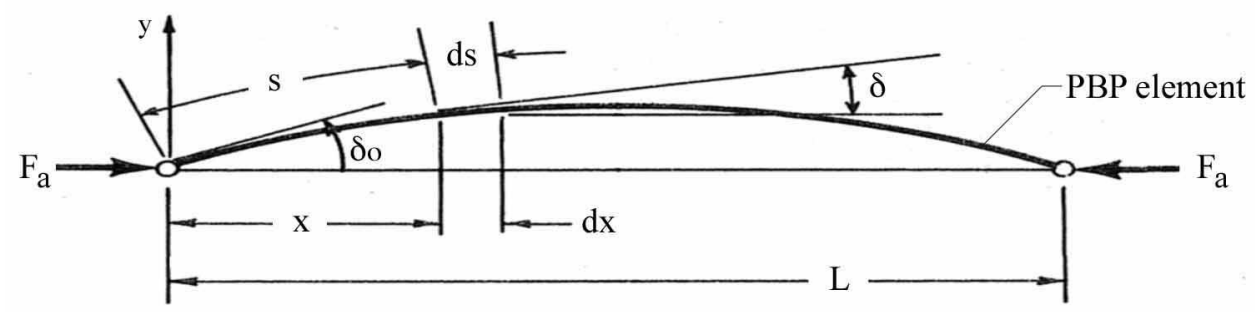

Figure 3 Analysis Terms and Conventions for Analysis of the PBP Actuator Arrangement

Figure 3 shows that the length along the surface of the element, s, and the length along the major axis of the element, $x$, are related by the curvature induced in the actuator. The angular coordinate, $\delta$ is maximized at the ends of the element, $\delta_{o}$ and goes to zero at the mid point.

One can consider the normal strain of any point in the PBP actuator at a distance y from the neutral axis through its thickness as:

$$
\varepsilon=\frac{y d \delta}{d s}=\frac{\sigma}{E}
$$

If one examines the individual beam element and assumes pure bending, then the following holds:

$$
\sigma=\frac{M y}{I}
$$

Accordingly, combining equations 5 and 6 with CLPT conventions and terminology, equation 7 is obtained:

$$
\frac{y d \delta}{d s}=\frac{M y}{D b}
$$

Because the externally applied moment loading in each section comes from the axial force, $\mathrm{F}_{\mathrm{a}}$ :

$$
M=-F_{a} y
$$

Substituting equation 8 into 7 yields: 


$$
\frac{d \delta}{d s}=-\frac{F_{a} y}{D b}
$$

Differentiating equation 9 with respect to s:

$$
\frac{d^{2} \delta}{d s^{2}}=-\frac{F_{a}}{D b} \operatorname{Sin} \delta
$$

Multiplying through by the integrating factor $2 d \delta / d s$ :

$$
2 \frac{d \delta}{d s} \frac{d^{2} \delta}{d s^{2}}=-2 \frac{F_{a}}{D b} \operatorname{Sin} \delta \frac{d \delta}{d s}
$$

Integrating equation 11 yields:

$$
\left(\frac{d \delta}{d s}\right)^{2}=2 \frac{F_{a}}{D b} \operatorname{Cos} \delta+a
$$

If one considers the addition of an applied moment via piezoelectric elements as generating an imperfection across the beam, then the unknown integrating factor, a, can be solved for, given that at $\mathrm{x}=0, \delta=\delta_{o}, d \delta / d s=\kappa$.

$$
\left(\frac{d \delta}{d s}\right)^{2}=2 \frac{F_{a}}{D b}\left(\operatorname{Cos} \delta-\operatorname{Cos} \delta_{o}\right)+\kappa^{2}
$$

With appropriate trigonometric substitutions and considering the negative root because $\mathrm{d} \delta$ is always negative:

$$
\frac{d \delta}{d s}=-2 \sqrt{\frac{F_{a}}{D b}} \sqrt{\operatorname{Sin}^{2}\left(\delta_{o} / 2\right)-\operatorname{Sin}^{2}(\delta / 2)+\frac{\kappa^{2} D b}{4 F_{a}}}
$$

For solution, a change of variable is as follows:

$$
\operatorname{Sin}(\delta / 2)=c \operatorname{Sin} \xi
$$

Where $\xi$ is a variable with the value $\pi / 2$ when $x=0$ and the value 0 when $x=L / 2$. Accordingly, when $x=0$ :

$$
c=\operatorname{Sin}\left(\delta_{o} / 2\right)
$$

Solving for $\delta$ and differentiating yields:

$$
\delta=2 \operatorname{Sin}^{-1}\left(\operatorname{Sin}\left(\delta_{o} / 2\right) \operatorname{Sin} \xi\right)
$$

$$
d \delta=\frac{2 \operatorname{Sin}\left(\delta_{o} / 2\right) \operatorname{Cos} \xi}{\sqrt{1-\operatorname{Sin}^{2}\left(\delta_{o} / 2\right) \operatorname{Sin}^{2} \xi}} d \xi
$$

Combining equations 14 through 17 with appropriate end values:

$$
\sqrt{\frac{F_{a}}{D b}} \int_{0}^{L / 2} d s=\frac{L}{2} \sqrt{\frac{F_{a}}{D b}}=\int_{0}^{\pi / 2} \frac{\operatorname{Sin}\left(\delta_{0} / 2\right) \operatorname{Cos} \xi}{\left(\sqrt{\left.\operatorname{Sin}^{2}\left(\delta_{o} / 2\right) \operatorname{Cos}^{2} \xi+\frac{\kappa^{2} D b}{4 F_{a}}\right)}\right)\left(\sqrt{1-\operatorname{Sin}^{2}\left(\delta_{0} / 2\right) \operatorname{Sin}^{2} \xi}\right)} d \xi
$$




\subsection{Overall Design}

\section{ACTUATOR DESIGN AND FABRICATION}

The actuator element was designed to generate deflections and maintain moment and bandwidth capabilities suitable for controlling the XQ-138 MAV. Toward that end, a PBP actuator element of the following geometry was laid out:

\section{Top View}

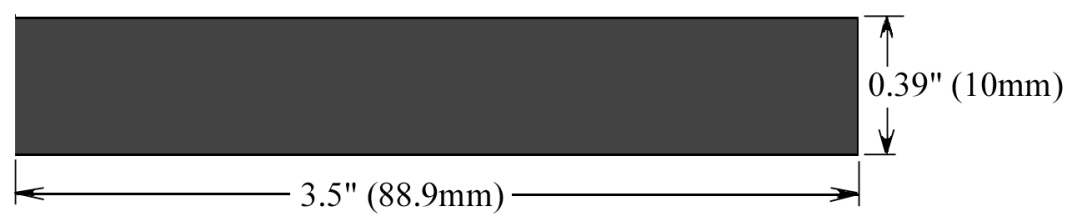

\section{Side View}

2 mil $(51 \mu \mathrm{m})$ thick aluminum substrate, 1 mil $(25 \mu \mathrm{m})$ bond on either side

7.5mil $(191 \mu \mathrm{m})$ thick PZT-5A piezoceramic sheets

\section{Fig. 4 PBP Grid Fin Actuator Geometry}

The grid fins which are employed on the XQ-138 family of MAVs are multicellular and provide pitch and yaw control to the aircraft. They have been designed to possess very low pitching moments about the pivot point and yet provide very high normal force gradients with deflection. These properties allow the aircraft to maintain stable flight in very gusty conditions and excellent levels of control authority throughout all flight regimes from hover, through transition and high speed airplane-mode flight. Figure 5 shows the grid-fins integrated on the lower fuselage of the aircraft.

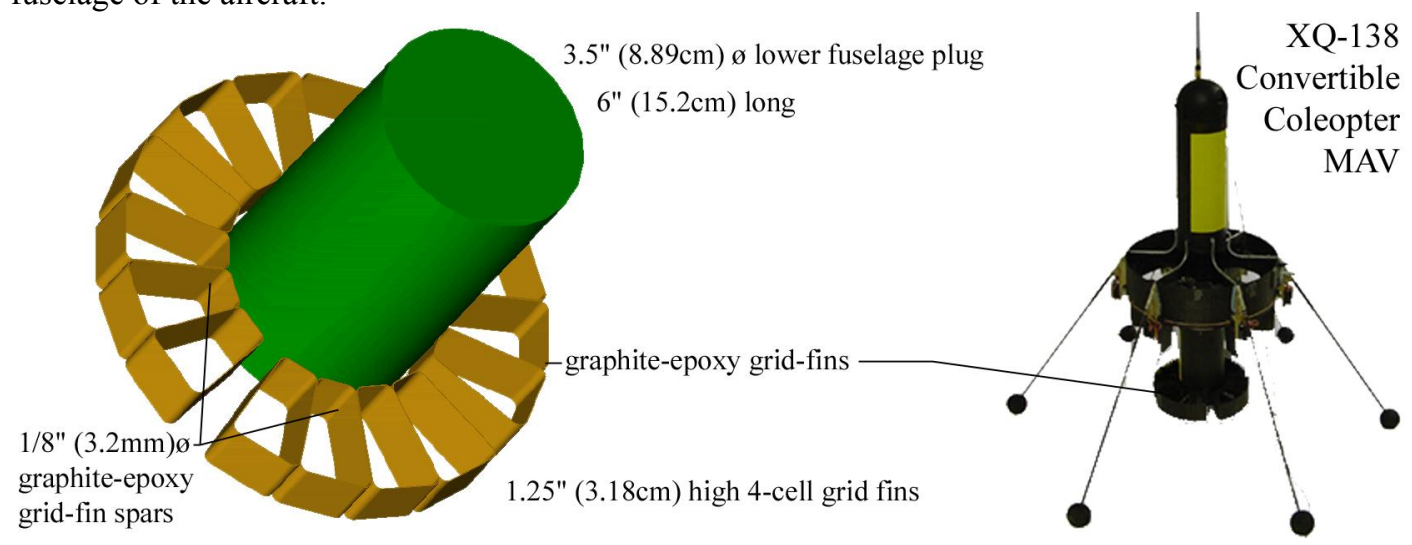

Fig. 5 Graphite-Epoxy Grid Fin Assembly on Lower Fuselage of XQ-138 MAV

To demonstrate the PBP actuator, a truncated fuselage demonstration rig was designed. This rig employed a sectioned lower fuselage and bearing assembly supporting a fully flightworthy grid fin equipped empennage.

\subsection{PBP Grid Fin Actuator Test Article Fabrication}

Prior to integration in a flightworthy aircraft, an experimental test rig was fabricated and tested. This rig employed all of the salient features of a flightworthy empennage, except that only one grid fin was used rather than a complete set of four and the fuselage tube was opened and truncated so that all components might be observed during operation. Figure 6 shows the layout of the test rig. 


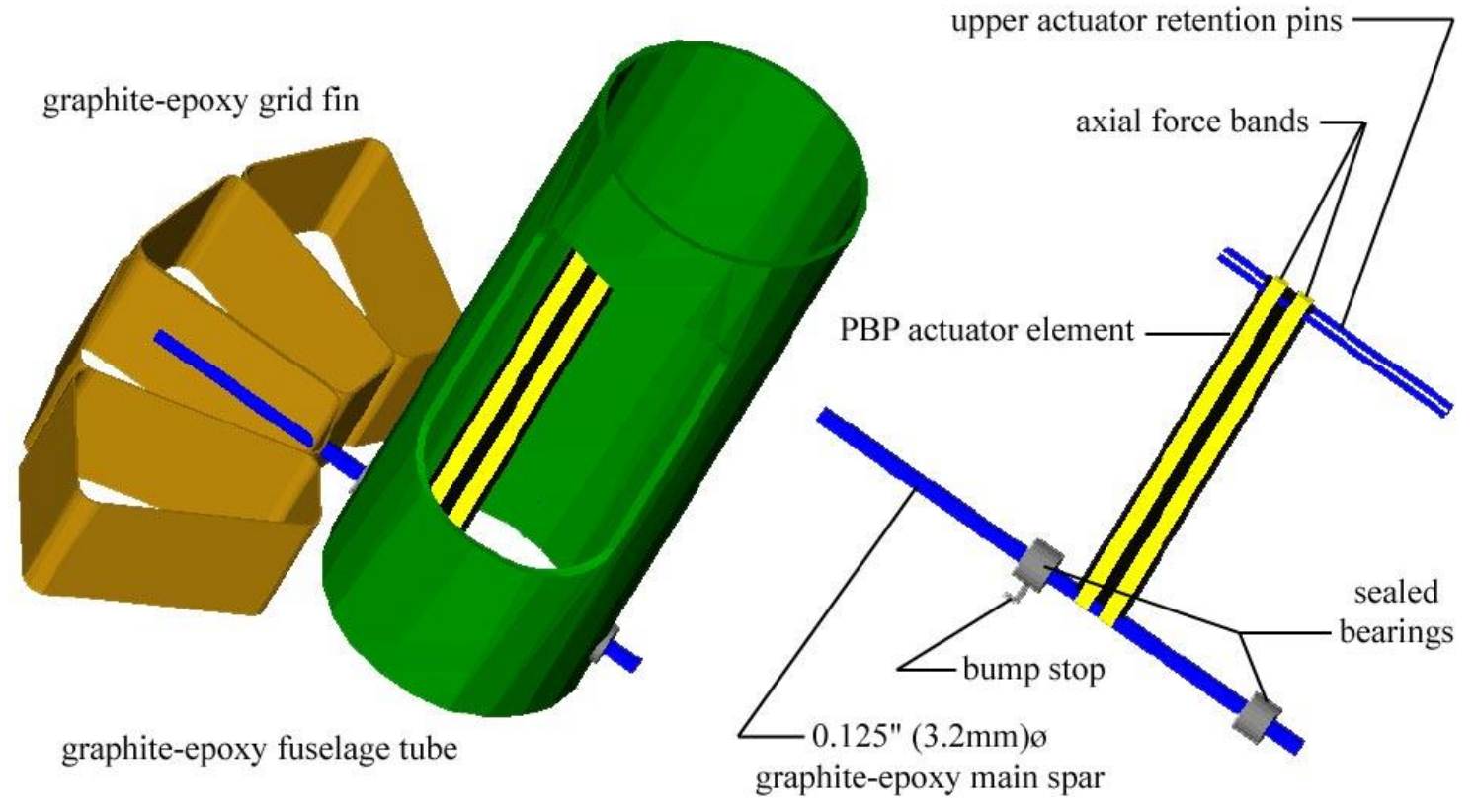

Fig. 6 Grid Fin Test Rig Assembly with Integral PBP Actuator and Structural Mounts

The graphite-epoxy structures were fabricated from Cyanimide 123 pre-impregnated graphite cloth while the PBP actuator element was laid up in a $250^{\circ} \mathrm{F}\left(121^{\circ} \mathrm{C}\right)$ high temperature cure so as to precompress the piezoceramic elements. The axial force bands were made from silicone elastic material and provided a scheduled amount of axial force so as to induce post-buckled behavior as seen in Fig. 2.

\subsection{Quasi-Static Bench Testing}

\section{EXPERIMENTAL TESTING AND RESULTS}

A series of experiments were conducted on the actuator assembly so as to verify both the analytical models of Section 2 and demonstrate the working principles of the actuator. Laser reflection techniques were used to measure grid fin angular deflections to $0.01^{\circ}$ of accuracy. Figure 7 shows the grid fin test rig assembly prior to mounting in the seismic test base.
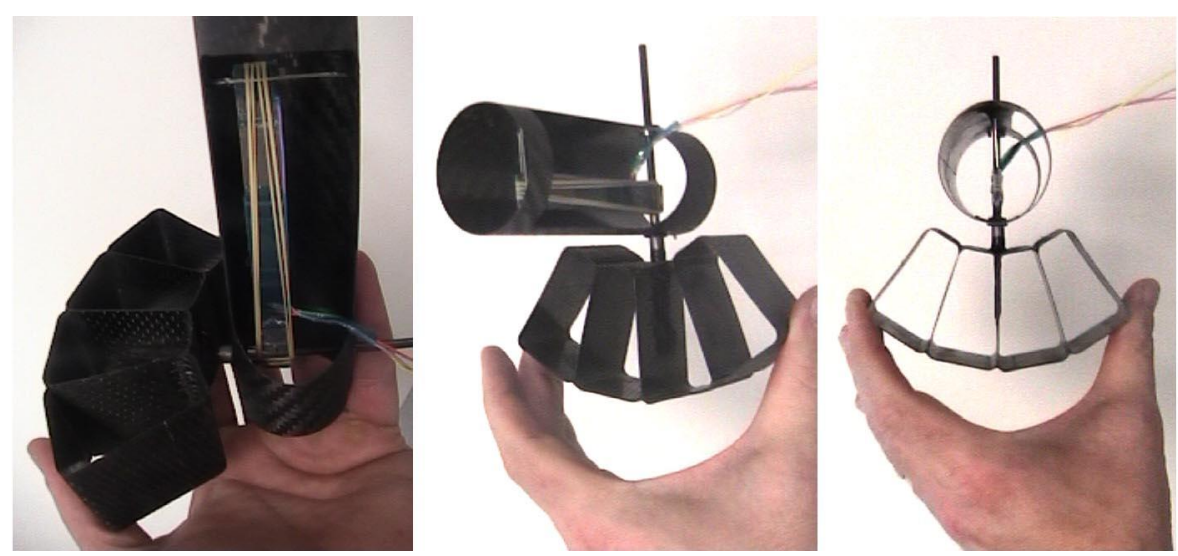

Fig. 7 Grid-Fin Test Rig Assembly Prior to Mounting on Seismic Base 
The first set of tests were conducted quasi-statically with driving signals being fed to the test apparatus at $1 \mathrm{~Hz}$. A sweep of voltage and axial force was made so as to determine just how expanded the design envelope can become. Figure 8 shows the deflection, $\delta_{0}$, as a function of applied voltage and axial force. It should be noted that the bump stops were set at $\pm 7^{\circ}$ so that tensile depoling and mechanical failure of the piezoceramic actuator elements could be avoided.

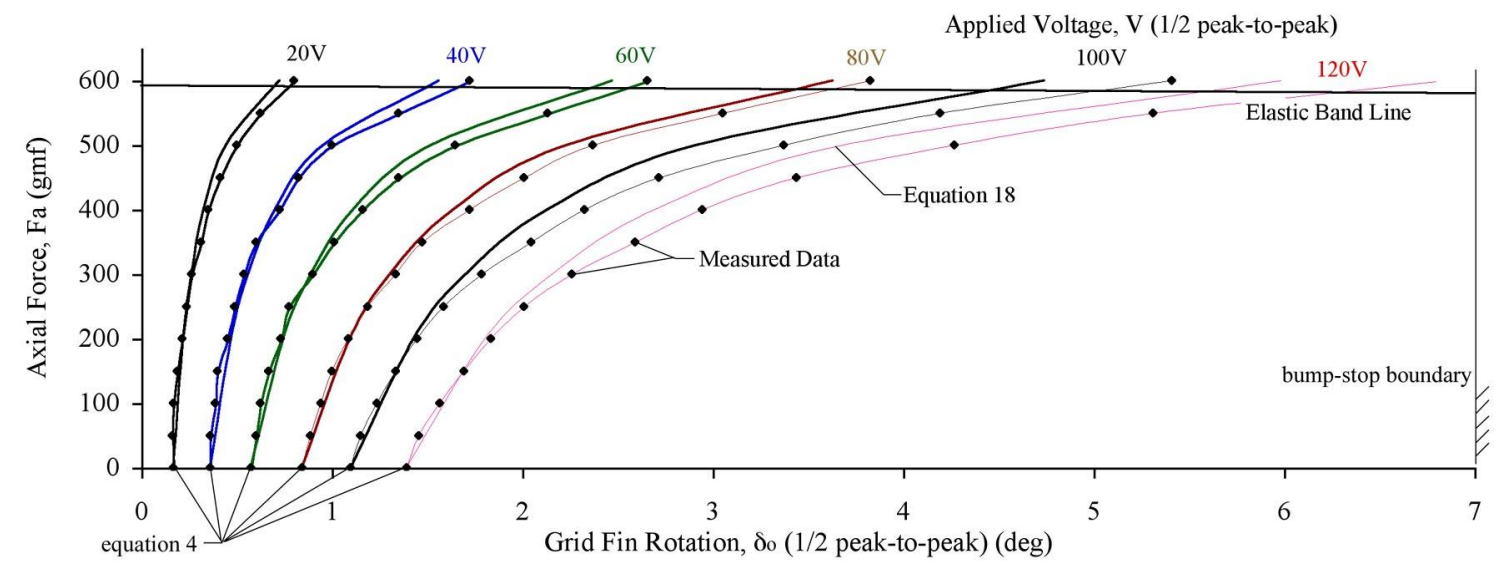

Fig. 8 Correlation of Grid Fin Deflection Angle, $\delta_{0}$, Applied Voltage and Axial Force, $F_{a}$

Of course, it is important for the overall benefit of the PBP system to be tracked in terms of total level of deflection amplification. Figure 9 shows the deflection trends with and without application of axial force, $F_{a}$ via the axial force bands.

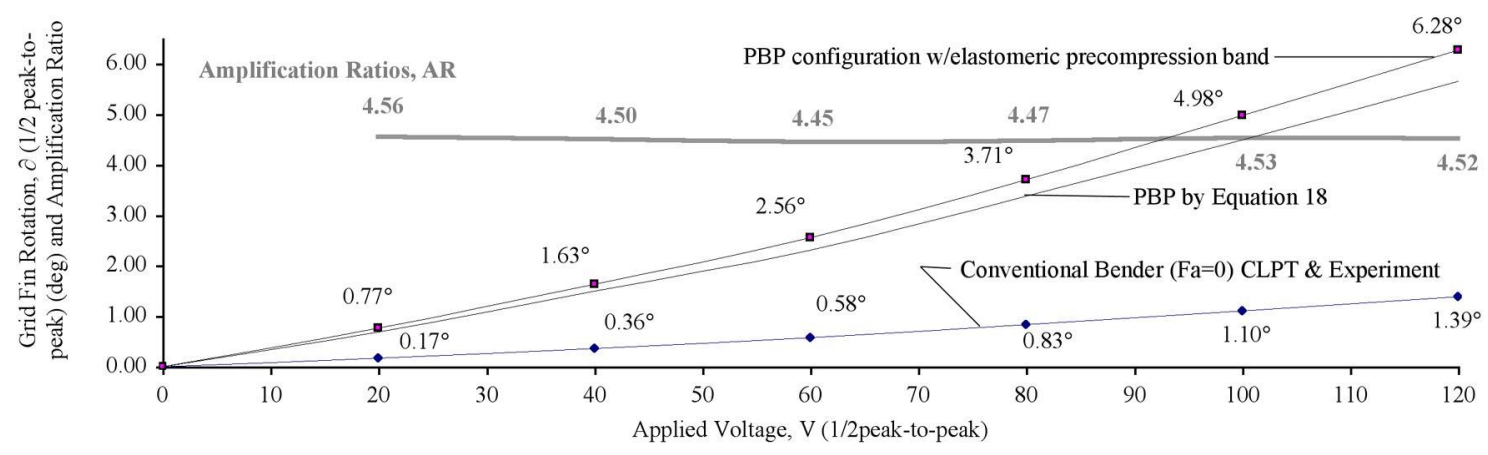

Fig. 9 Performance Comparison of PBP and Conventional Actuator Elements

From Fig.'s 8 and 9, it can be seen that the PBP analysis techniques presented in Section 2 underpredicted the amount of deflection by up to $10 \%$. It is suspected that creep effects induced such disparity between theory and experiment as the difference between the two trendlines grew as the period was increased from $1 \mathrm{sec}$. It should also be noted that the amplification ratio between the conventional bender line $(\mathrm{Fa}=0)$ and the measured PBP deflections is relatively steady at approximately $\mathrm{AR}=4.5$.

\subsection{Dynamic Bench Testing}

A series of dynamic bench tests were conducted to determine the frequency response of the actuator. Laser reflection techniques were used to determine performance. The fin assembly was mounted to a seismic test rig as shown in Fig. 10. 

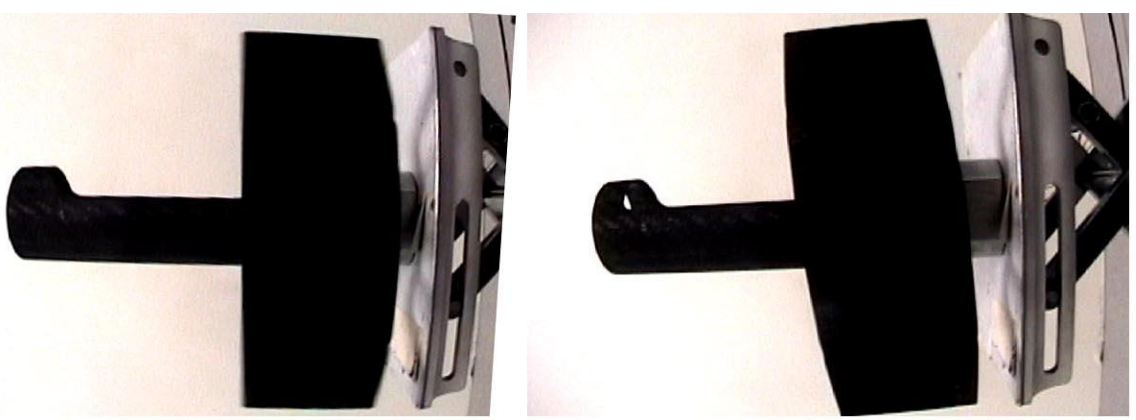

Fig. 10 Grid Fin Test Article Mounted on Seismic Base Unactuated and Undergoing Dynamic Deflections

Because actuator bandwidth is so important to aircraft flight control systems, the following Bode amplitude plots were obtained for both the unamplified version of the actuator $(\mathrm{Fa}=0)$ and the PBP configuration with the elastic band in place.

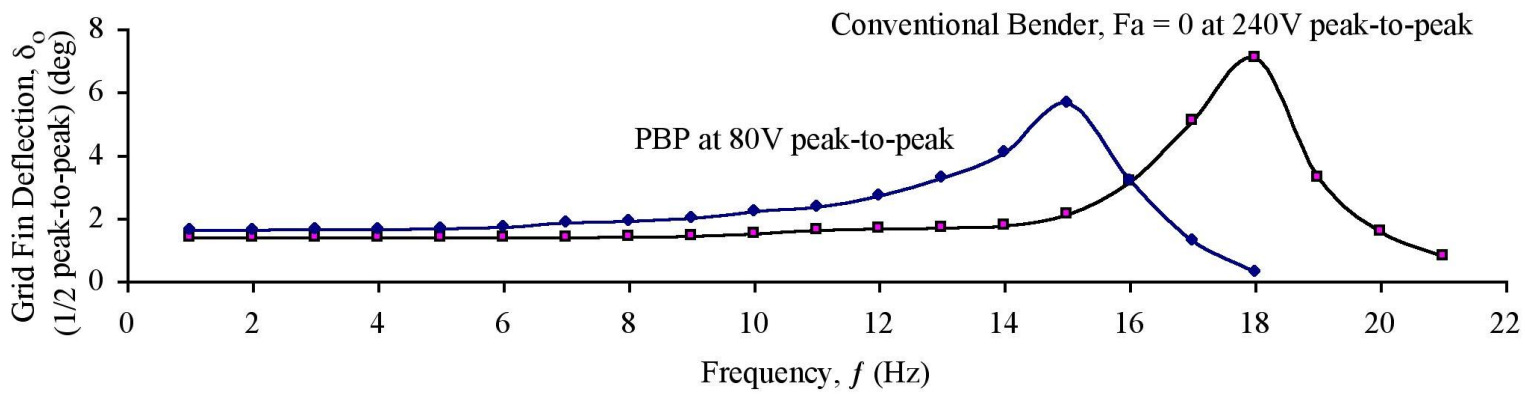

Fig. 11 Dynamic Performance of Conventional Bender and PBP Variants of the Grid Fin Actuator Assembly

From Figure 11 it can be seen that the dynamic performance is degraded as the level of axial force is increased from 0 to just under $1.32 \mathrm{lb}(600 \mathrm{gmf}, 5.87 \mathrm{~N})$, with resonance peaks moving from 18 to $15 \mathrm{~Hz}$. However, given the performance of conventional flight control servoactuators, this is still far superior to those that are typically available on the open market and those originally used on the XQ-138.

\subsection{Wind Tunnel Testing}

A series of wind tunnel tests were conducted to ensure that no flutter or divergence tendencies were present and that deflections remain steady with airspeed. Wind tunnel testing was conducted in the Auburn University 3' x 4' $(91 \mathrm{~cm} \times 122 \mathrm{~cm})$ subsonic wind tunnel at speeds up to $120 \mathrm{ft} / \mathrm{s}(71 \mathrm{kts}, 82 \mathrm{mph}, 36.5 \mathrm{~m} / \mathrm{s})$. Figure 12 shows that the deflections are neither amplified nor degraded with increased airflow up through the test speeds. Because the aerodynamic center, center of gravity and center of pressure are all aligned with the hinge line of the grid fins, adverse pitch deflections and flutter tendencies are effectively nulled as seen in Fig. 12.

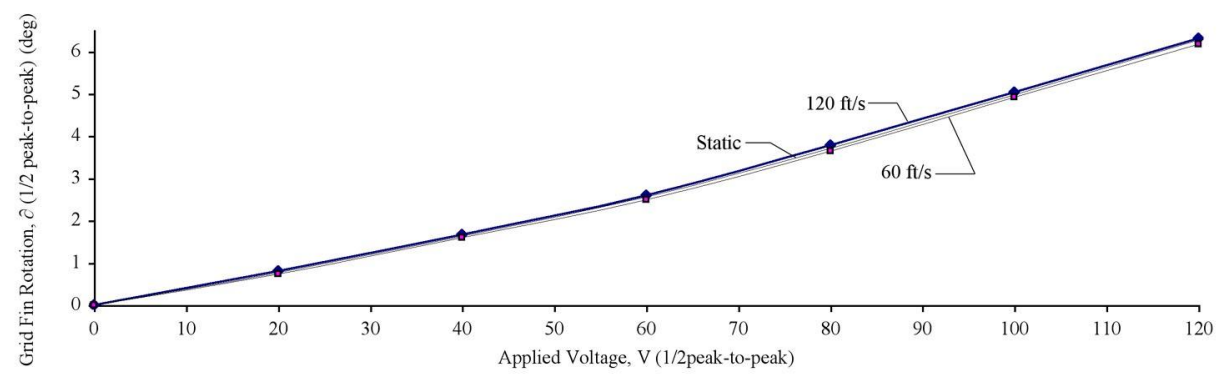

Fig. 12 Grid Fin Performance in Wind Tunnel up to $120 \mathrm{ft} / \mathrm{s}(71 \mathrm{kts}, 36.5 \mathrm{~m} / \mathrm{s})$ 


\subsection{Flight Testing}

Following successful wind tunnel tests, a complete empennage assembly was fabricated and flown on an autonomous variant of the XQ-138. The PBP empennage assembly weighed substantially less than its conventional electromagnetic servoactuator driven counterpart. Fig. 13 shows the empennage assembly prior to integration into the aircraft.

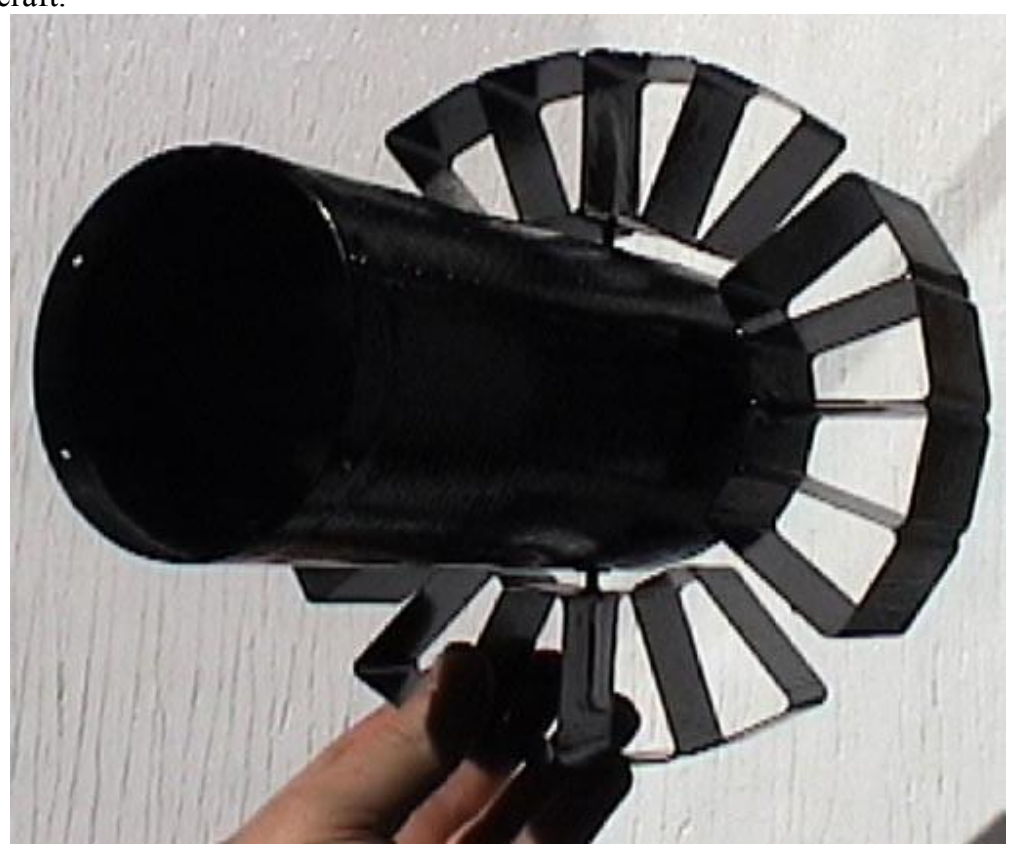

Fig. 13 PBP Grid Fin Assembly Prior to Integration into the Flightworthy Fully Autonomous XQ-138 Variant

Flight testing confirmed that control authority of the conventional empennage was matched while responsiveness was increased nearly three-fold. The substantial weight reduction in the empennage induced such a significant shift in center of gravity that components in the nose of the XQ-138 needed to be rearranged so as to maintain appropriate weight and balance. Figure 14 shows the modified variant of the XQ-138 in flight.
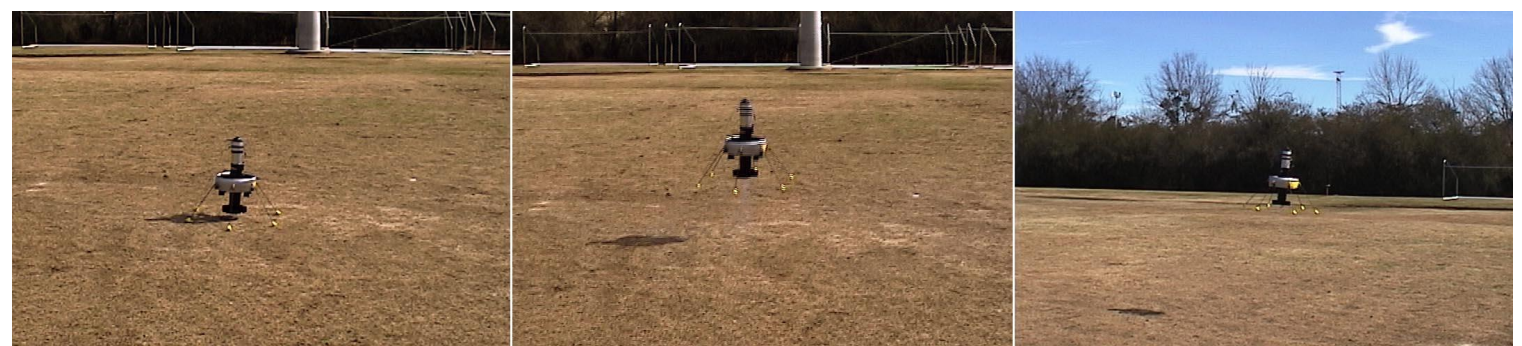

Fig. 14 XQ-138 with PBP Grid-Fin Empennage During Autonomy Package Testing

\subsection{Integration Characteristics and Comparison}

Significant benefits are clearly obtained by switching from conventional electromagnetic servoactuators to PBP actuators. Figure 15 shows the weight savings in terms of aircraft operating empty weight (OWE) fraction. Because the PBP actuators have no push rods, linkages or heavy motors with windings, they are significantly lighter than conventional electromechanical servoactuators. Because PBP actuators operate with high voltage rather than high current, the weight of the leads was reduced dramatically and servoactuator generated EMI was essentially eliminated (an important characteristic in such tight confines as an aircraft fuselage). Their low power consumption also induced a shrinkage in the size of the power supply systems on board the aircraft which further aided in boosting mission performance. Unlike conventional servoactuators, the PBP actuator is solid state so the part count, slop and deadband levels are one to two orders of magnitude below conventional servoactuators as seen in Table 1. 


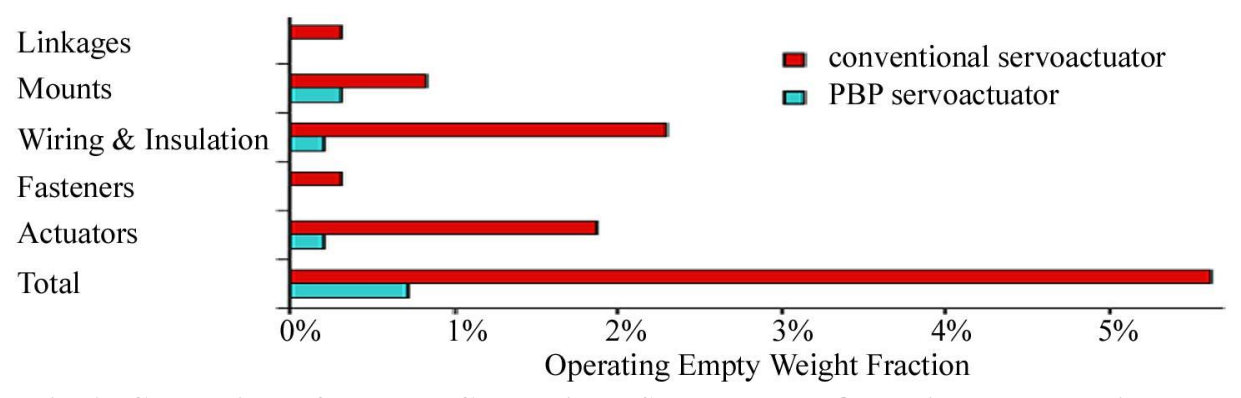

Fig. 15 Comparison of PBP and Conventional Servoactuator Operating Empty Weight Fractions for the XQ-138

Power consumption was measured at the maximum deflections at the maximum frequency for both classes of actuators. From Table 1, it can be seen that both the current and total power consumption levels of the PBP class actuators are significantly lower than conventional actuators. Because the measured deadband and slop was reduced by two orders of magnitude, the tendency to be susceptible to buffet vibrations is also essentially eliminated. Finally, the great simplicity of the PBP system is seen in a part count reduction which will ultimately help keep manufacturing costs low.

Table 1 Comparison of PBP and Conventional Electromechanical Pitch and Yaw Flight Control Actuator Systems

\begin{tabular}{|l|c|c|}
\hline & Conventional Servoactuaor & PBP Actuator \\
\hline max power & $24 \mathrm{~W}$ & $100 \mathrm{~mW}$ \\
\hline max current & $5 \mathrm{~A}$ & $1.4 \mathrm{~mA}$ \\
\hline mass & $108 \mathrm{~g}$ & $14 \mathrm{~g}$ \\
\hline slop & $1.6^{\circ}$ & $0.02^{\circ}$ \\
\hline break frequency & $3 \mathrm{~Hz}$ & $21 \mathrm{~Hz}$ \\
\hline part count & 56 & 6 \\
\hline
\end{tabular}

\section{CONCLUSIONS}

It can be concluded that a new class of actuators employing axial forces to induce post-buckled deflection amplification possesses significant benefits over conventional piezoelectric and electromechanical servoactuators. Classical laminated plate theory models are shown to accurately capture the performance of the actuators with no axial force. A new model designed to capture the large deformation behavior of post-buckled precompressed actuators is shown to work very well. A series of piezoelectric specimens were built to demonstrate the utility of the new post buckled precompressed (PBP) actuator scheme. These actuator elements were designed as actuators for grid fins for a new class of subscale UAVs, in particular, the XQ-138 convertible coleopter. An extensive series of tests with varying levels of axial precompression showed that static deflections could be controllably magnified approximately 4.5 times over conventional levels with excellent agreement between theory and experiment. The prototype flight control actuators were designed to nominally generate flight control deflections up to $\pm 5^{\circ}$ at rates in excess of $15 \mathrm{~Hz}$. Because the PBP actuators are much simpler and operate as highly efficient solid state actuators, they consume $0.4 \%$ of the power, weigh $87 \%$ less, move seven times faster and possess an order of magnitude less parts than conventional servoactuators. Because they do not employ any linkages or pushrods, their slop levels are reduced by more than $98 \%$. The result of these benefits is that the operating empty weights of the XQ-138 family is enhanced by nearly $4 \%$ while gross performance is improved in every other measure.

\section{ACKNOWLEDGMENTS}

The authors would like to acknowledge the outstanding contributions of the many students and colleagues who helped with this study including Mr. Christoph Burger, Professor Eelco Jansen, Mr. Koen Artois, Professor R. Steven Gross and Mr. Bill Holbrook. This study was sponsored by the AAL and the Faculty of Aerospace Engineering of the Technical University of Delft, Netherlands. 


\section{REFERENCES}

1. Crawley, E. F. and De Luis, Javier, "Use of Piezoelectric Actuators as Elements of Intelligent Structures," AIAA Journal, Vol. 25, No. 10, Oct. 1987, pp. 987-997.

2. Prechtl, E.F. and Hall, S. R., "Design of a High Efficiency, Large Stroke Electromechanical Actuator," Journal of Smart Materials and Structures, published by IOP Publishing, Bristol, UK, Vol. 8, pp. 13 - 30, 1999.

3. A. J. Moskalik and D. Brei, 1998, "Analytical Dynamic Performance Modeling for Individual C-Block Actuators," Journal of Vibrations and Acoustics, Vol. 121, pp. 221-230.

4. A.J. Moskalik and D. Brei, 1999, "Force-Deflection Behavior of Piezoelectric C-Block Actuator Arrays," Smart Materials and Structures, Vol. 8, pp.531-543.

5. J. Ervin and D. Brei, December 1998, "Recurve Piezoelectric-Strain-Amplifying Actuator Architecture", IEEE/ASME Transactions on Mechatronics, Vol. 3, No. 4, pp. 293-301.

6. Clement, J., Brei, D., Moskalik, A., and Barrett, R., "Bench-Top Performance Characterization of a C-Block Driven Active Flap System," proceedings of the 39th Structures, Structural Dynamics and Materials Conference 20 - 23 April 1998, Long Beach, CA, published by the American Institute of Aeronautics and Astronautics, Washington, D.C. 1998, paper no. AIAA-98-2039.

7. Schwartz, R. W., Laoratanakul, P., Nothwang, W. D., Ballato, J., Moon, Y. and Jackson, A., "Understanding Mechanics and Stress Effects in Rainbow and Thunder Actuators," SPIE Smart Structures and Materials, Active materials: Behavior and Mechanics, 3992, 363 (2000).

8. Barrett, R., Burger, C., and Melian, J. P., "Recent Advances in Uninhabited Aerial Vehicle (UAV) Flight Control with Adaptive Aerostructures," Proceedings of the $4^{\text {th }}$ European Demonstrators Conference, $10-15$ December 2001, Edinburgh, Scotland.

9. Barrett, R. and Lee, G., "Design Criteria, Aircraft Design, Fabrication and Testing of Sub-Canopy and Urban Micro-Aerial Vehicles," proceedings of the AIAA/AHS International Powered Lift Conference, Alexandria, Virginia, 1 November 2000.

10. Barrett, R., and Stutts, J., "Development of a Piezoceramic Flight Control Surface Actuator for Highly Compressed Munitions," proceedings of the 39th Structures, Structural Dynamics and Materials Conference 20 - 23 April 1998, Long Beach, CA, published by the American Institute of Aeronautics and Astronautics, Washington, D.C. 1998, paper no. AIAA-98-2034.

11. Barrett, R., "Adaptive Aerostructures, Improving High Performance, Subcale Military UAVs," $45^{\text {th }}$ AIAA/ASME/ASCE/AHS/ASC Structures, Structural Dynamics and Materials Conference, $12^{\text {th }}$ AIAA/ASME/AHS Adaptive Structures Conference 19 - 22 April 2004/Palm Springs, California, AIAA paper no. 2004-1886.

12. Lesieutre, G.A., and C.L. Davis, "Can a Coupling Coefficient of a Piezoelectric Actuator be Higher Than Those of Its Active Material?," Journal of Intelligent Materials Systems and Structures, Vol. 8, 1997, pp. 859-867.

13. Lesieutre, G. A. and Davis, C. L., "Transfer Having a Coupling Coefficient Higher than its Active Material," US Pat. 6,236,143 issued 22 May 2001.

14. Jones, R. M., "Micromechanical Behavior of a Lamina," Mechanics of Composite Materials, Hemisphere Publishing Corporation, New York, 1975 